\title{
How Does Media Coverage of Entrepreneurship Affect Entrepreneurial Decision-Making of Returning Migrant Workers in China? A Moderated Mediation Model
}

\author{
Jinfa Liu, ${ }^{1}$ Jie Liu $\left(\mathbb{D},{ }^{2}\right.$ Donghui Zheng $\mathbb{D}^{1},{ }^{1}$ Yan Han $\mathbb{D}^{1},{ }^{1}$ and Yijin Wu $\mathbb{D}^{3}$ \\ ${ }^{1}$ School of Management Science, Qufu Normal University, Rizhao, Shandong 276826, China \\ ${ }^{2}$ School of Government Management, Beijing Normal University, Beijing 100875, China \\ ${ }^{3}$ School of Translation Studies, Qufu Normal University, Rizhao, Shandong 276826, China \\ Correspondence should be addressed to Yijin Wu; wuyijin9972@126.com
}

Received 16 November 2021; Revised 26 December 2021; Accepted 6 January 2022; Published 24 January 2022

Academic Editor: Xinsheng Xu

Copyright $(2022$ Jinfa Liu et al. This is an open access article distributed under the Creative Commons Attribution License, which permits unrestricted use, distribution, and reproduction in any medium, provided the original work is properly cited.

As an important measure to help returning migrant workers (RMWs) to make entrepreneurial decisions, media coverage received much attention in recent years in China. In this study, we take the hierarchical regression method to examine how media coverage of entrepreneurship (MCE) affects the entrepreneurial intention (EI) and entrepreneurial decision-making (ED) of RMWs. The results prove that MCE has a significant positive effect on EI and ED of RMWs and that the entrepreneurial knowledge (EK) negatively moderates the relationship between MCE and EI of RMWs and positively moderates the mediating effect of EI. Meanwhile, we also find that risk propensity (RP) of RMWs plays a positive role in the above-mentioned relationship. The obtained results enlighten us on the fact that we should not only pay attention to the agenda-setting effect of the media coverage but also carry out differentiated MCE for RMWs with different EKs and RP.

\section{Introduction}

In recent years, entrepreneurial decisions of returning migrant workers (RMWs) continue to emerge. Accordingly, entrepreneurship has become the third choice for RMWs to work either in agriculture or in cities [1]. In order to attract more RMWs to carry out entrepreneurial activities, the State Council of China has encouraged social media to carry out publicity on entrepreneurial support policies. As a consequence, typical entrepreneurs and cases of entrepreneurship are often seen in the media.

The above policy recommendations are obviously based on the assumption that the media has significant influence. However, it is wondered whether there is an agenda-setting effect of Chinese media on encouraging RMWs in entrepreneurship. If this effect does exist, how does it work, and what factors will interfere with it? In order to answer the questions, we conducted a review on previous relevant studies, based on which three main perspectives were identified. One is that the media is an important part of the social environment. The public's awareness of the importance of the issues is often the result of intensive coverage of them by the news media [2]. When the media emphasizes a topic, the public will consider it as an important issue, and thus they will pay more attention to such problems or behaviors [3]. Among the media, television, Internet, newspapers, and magazines are the main channels for migrant workers to obtain information. The second perspective is that there is close relationship between media coverage and enterprises. Some studies have demonstrated the social communication significance of media coverage on entrepreneurship [4] and pointed out that media coverage had an important influence on businesses' reputations, resources, and performance [5] and also a significant positive impact on securities market returns and investor optimism $[6,7]$. The third perspective highlighted the propensity of MCE. Studies found that media coverage of enterprises is tendentious [8] and that the coverage of entrepreneurs tends to be positive and portray entrepreneurs as celebrity chief executive officers [9]. In addition, the media tend to describe 
entrepreneurial failure as a necessary stage and believe that failure is the mother of success [10].

Previous studies have made important findings on the media's function of agenda-setting effect, which focus on how media in Europe and the United States report on new start-ups and how media coverage affects business operations [11], but less consideration of RMWs is given to China's situation. In this study, based on agenda-setting theory and planned behavior theory, we construct a moderated mediation model to explore the impact of MCE on the ED of RMWs. The main contents of this study include literature review, research hypothesis, research design, and empirical test, as well as policy implications of the study.

\section{Literature Review and Research Hypothesis}

2.1. MCE and EI. Agenda setting refers to the mass media's emphasis on certain issues and the formulation of an agenda for the ideas of the public, by which the media disseminate knowledge and information. There is a strong and positive relationship between the focus of media coverage and the agenda considered by the public [12]. Media agenda-setting effect exists not only in the field of political communication, but also in commercial communication. Through agendasetting effect, the media enable people to better accept and understand entrepreneurship and identify with entrepreneurs and their daily behavior [13].

News reported by the media on a corporation not only reflects corporate activities but also affects the public's attitude towards the enterprise [14]. In this way, the public could easily recognize the social legitimacy of ED, the positive image of entrepreneurs, and the positive function of entrepreneurship. With the increase of media exposure and the propensity to conduct positive coverage, the public can better assess start-ups' development prospects $[15,16]$. Previous studies have found that media coverage of entrepreneurial models can have an impact on the public's EI [17]. Therefore, based on agenda-setting theory, we make the following hypothesis.

$\mathrm{H1}$ : MCE has a positive and significant impact on the EI of RMWs.

2.2. EI and ED. According to the theory of planned behavior, EI refers to people's subjective propensity to engage in entrepreneurial activities, and it is the premise of ED [18]. Here, ED means that a person not only has the intention to start a business but also shows specific entrepreneurial behavior, such as writing a business plan, forming an entrepreneurial team, and purchasing or leasing facilities and equipment $[19,20]$. Previous studies have shown that EI and perceived behavior control can explain the choice of behavior [21]. When people have strong EI, they are more likely to carry out entrepreneurial action. Therefore, according to the theory of planned behavior, it is reasonable to speculate that the EI of RMWs will stimulate ED. Thus, the second hypothesis is put forward as follows.

$\mathrm{H} 2$ : The EI of RMWs has a significant positive impact on their ED.
2.3. The Mediating Effect of EI. Mass media can affect people's attitude and behavior [22]. The media guided entrepreneurial practice through multiple functions such as information transmission, public opinion guidance, and social shaping [23]. The theory of planned behavior holds that social norms are important environmental factors affecting individual decisionmaking. The publicity degree of mass media on entrepreneurship is an important embodiment of social norms [24]. Therefore, the media's publicity and coverage of entrepreneurship would stimulate individuals to carry out social learning and imitation, so as to realize entrepreneurship.

Some studies have examined the mediating role of EI between entrepreneurial self-efficacy and ED [25]. Some other studies have pointed out that EI was a necessary condition for ED and that the factors would indirectly affect ED through EI [26]. This showed that MCE could promote the EI of RMWs and further stimulate their entrepreneurial decisions. Therefore, we propose the following two hypotheses:

$\mathrm{H} 3$ : MCE has a positive and significant impact on the ED of RMWs

$\mathrm{H} 4$ : The EI of RMWs plays a mediating role between MCE and ED

2.4. The Moderating Effect of EK. The agenda-setting effect of media may be influenced by individual's EK. One possibility is that EK helps people to identify and take advantage of opportunities, thereby stimulating their EIs, which in turn lead to entrepreneurial decisions [27]. Another possibility is that people with EK will have a deeper understanding of entrepreneurial risks, and thus they will make entrepreneurial decisions more carefully $[28,29]$. This means that if the public has personal experience and knowledge of entrepreneurship, then the dependence on media coverage information will be reduced, and the media agenda-setting effect will be weakened [30]. When the public lacks direct experience and relevant knowledge of entrepreneurship, the role of the media will be more obvious [31]. Compared with RMWs who lack EK, the EI of RMWs with rich EK is less affected by media coverage, and vice versa. Accordingly, we can propose hypothesis $5 \mathrm{a}$.

H5a: EK negatively moderates the relationship between MCE and EI of RMWs.

EK can enhance the ability of individuals to integrate and utilize entrepreneurial resources, which play an important role in the establishment of new enterprises [32]. EK could help entrepreneurs solve the problems they face in starting a business and thus can make them more willing to carry out entrepreneurial practice $[33,34]$. It can be seen that under the premise of certain EI, RMWs with rich EK would tend to make entrepreneurial decisions. Accordingly, we can propose the following hypothesis.

$\mathrm{H} 5 \mathrm{~b}$ : EK positively moderates the relationship between the EI and ED of RMWs.

2.5. The Moderating Effect of RP. Since RP affects individual's decisions [35], the entrepreneurial process is a risk decisionmaking process, and individuals tend to take or avoid specific risks [36]. According to risk theory, the amount of 
media coverage will affect the public's cognition of some events and then affect the individual's understanding of risk [37]. Since individuals with high RP were more likely to underestimate the risk under certain circumstances [38, 39], they were more likely to have EI under the influence of a large amount of positive entrepreneurial coverage in the media. Thus, we can propose the following hypothesis.

H6a: RP positively moderates the relationship between the MCE and the EI of RMWs.

Although intention can predict behavior, people with EIs do not necessarily make entrepreneurial decisions after considering risks. ED of RMWs will be different under the risk and uncertainty [40]. The lower people's risk aversion is, the easier it is to find better business opportunities and the more likely they are able to engage in entrepreneurial activities [41, 42]. Thus, the RP could influence the decisions of potential entrepreneurs to create new enterprises [43, 44]. Hence, we can infer the following hypothesis.

H6b : RP positively moderates the relationship between the EI and ED of RMWs.

2.6. The Moderated Mediating Effect. We will further explore the size of mediating effect of RMWs' EI moderated by EK and RP. When the RMWs have rich EK and high RP, MCE will have a strong impact on ED by affecting the EI. Therefore, based on the assumptions $5 \mathrm{a}, 5 \mathrm{~b}, 6 \mathrm{a}$, and $6 \mathrm{~b}$, we further assume the following:

H7a: EK positively moderates the mediating effect of EI of RMWs between MCE and ED

H7b: RP positively moderates the mediating effect of EI of RMWs between MCE and ED

\section{Research Design and Empirical Results}

3.1. Research Design. In this section, we investigate the relationship between these five variables and examine the impact of MCE on the ED of RMWs. The theoretical model is shown in Figure 1.

3.2. Variable Measurement. A five-point Likert scale is used to measure the five latent variables of MCE, EI, ED, EK, and $\mathrm{RP}$, and the response options range from 1 (strongly disagree) to 5 (strongly agree).

According to Farmer [45], we use four items to measure variable ED: (1) I have spent a lot of time on a hometown entrepreneurship project; (2) I have invested in a hometown entrepreneurship project; (3) I have found a partner to implement this hometown entrepreneurship project; (4) I have determined the company name, business scope, and registered the trademark. Cronbach's $\alpha$ is 0.924 .

In order to measure variable MCE, we refer mainly to the questionnaire topic in the survey of Global Entrepreneurship Monitor [46]. The measurement includes four items: (1) entrepreneurial stories of RMWs often appear in media coverage; (2) I often see RMWs as typical examples of successful entrepreneurship in media coverage; (3) I often see entrepreneurial support policies for RMWs in media coverage;
(4) I will often pay attention to media coverage on the entrepreneurship policy of RMWs. Cronbach's $\alpha$ is 0.855 .

Recalling Linan and Chen [47], we establish four items to measure variable EI: (1) my career goal is to become an entrepreneur; (2) I will try my best to start my own company; (3) I have seriously considered the issue of returning home to start a business; (4) I am determined to return home to establish an enterprise in the future. Cronbach's $\alpha$ is 0.924 .

Referring to Rosário [48], we design four items to measure variable EK: (1) I have a good understanding of the policy and legal knowledge related to entrepreneurship; (2) I have a good understanding of marketing, financial management, operation management, and other knowledge related to entrepreneurship; (3) I have gained some EK, skills, and experience from practice (working experience, entrepreneurial experience, and so on); (4) starting from my entrepreneurial experience and knowledge, I can capture entrepreneurial opportunities. Cronbach's $\alpha$ is 0.900 .

Invoking Zhao [49] and Paço [50], we investigate three items to measure variable RP: (1) I like to do uncertain and risky things; (2) if the rate of return is high enough, I am willing to take great risks; (3) I am happy to start a business under uncertain circumstances. Cronbach's $\alpha$ is 0.819 .

3.3. Data Collection. A total of 50 questionnaires were collected in the presurvey, and Cronbach's $\alpha$ of each potential variable was greater than 0.7 , indicating that the internal consistency of the scale was good. Then, according to the results of confirmatory factor analysis, we deleted all items whose factor load was less than 0.5 and sent out a formal questionnaire. The participants of this study were RMWs who attended the entrepreneurship training in $\mathrm{R}$ City, S Province, China, from September to December 2019. A total of 330 questionnaires were distributed, and 243 were recovered, among which 27 were invalid and 216 were valid. Table 1 shows the details.

3.4. Model Setting. Hierarchical regression analysis is used to test the main effects of MCE on the EI and ED of RMWs. The main effect basic regression model is shown in the following equations:

$$
\begin{aligned}
\mathrm{EL}_{i} & =\beta_{0}+\beta_{1} \mathrm{MCE}_{i}+\beta_{2} c_{i}+\varepsilon_{i}, \\
\mathrm{ED}_{i} & =\alpha_{0}+\alpha_{1} \mathrm{MCE}_{i}+\alpha_{2} c_{i}+\varepsilon_{i} .
\end{aligned}
$$

When we test the mediating effect of EI of RMWs, we follow not only (1) and (2) but also the following equation:

$$
\mathrm{ED}_{i}=\gamma_{1} \mathrm{MCE}_{i}+\gamma_{2} \mathrm{EL}_{i}+\gamma_{3} c_{i}+\varepsilon_{i} .
$$

We first analyze the $\alpha_{1}$ of (1) and then enter the test of the $\beta_{1}$ of (2) and the $\gamma_{2}$ of (3). If they are all significant, we continue to test the $\gamma_{1}$ of (3). If $\gamma_{1}$ is not significant, it indicates that the EI has a complete mediating effect. Otherwise, it has only a partial mediating effect. When $\beta_{1}$ of (2) or $\gamma_{2}$ of (3) is not significant, we do Sober test to test $Z=\gamma_{1} \gamma_{2} /\left(\gamma_{1}^{2} S_{\gamma_{2}}^{2}+\gamma_{2}^{2} S_{\gamma_{1}}^{2}\right)^{1 / 2}$, in which $S \gamma_{1}$ and $S \gamma_{2}$ are the standard errors of $\gamma_{1}$ and $\gamma_{1}$, respectively. If the $Z$ is 


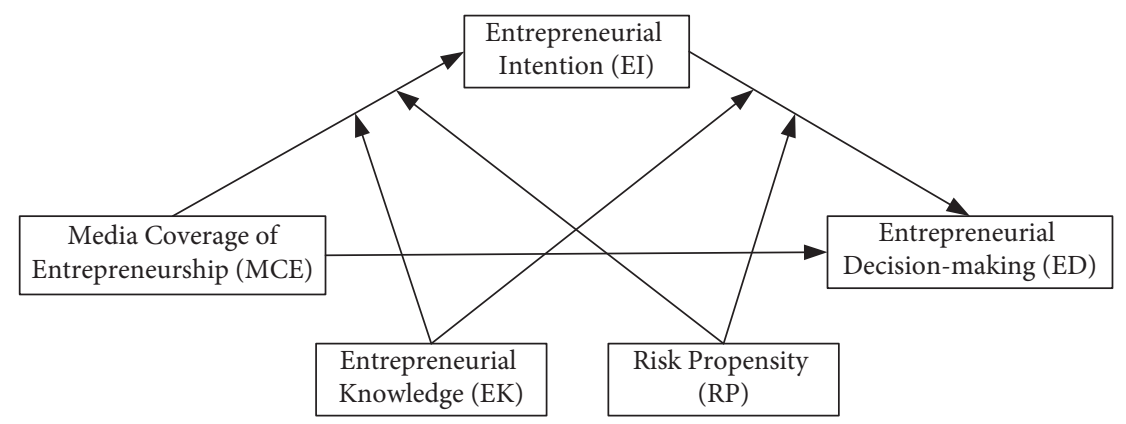

Figure 1: Theoretical model of this study.

TABle 1: Sample descriptive statistics.

\begin{tabular}{|c|c|c|c|}
\hline Variables & Category & Sample size & Sample proportion $(\%)$ \\
\hline \multirow{2}{*}{ Gender } & Male & 118 & 54.63 \\
\hline & Female & 98 & 45.37 \\
\hline \multirow{4}{*}{ Age } & Under 24 & 38 & 17.59 \\
\hline & $25-34$ & 86 & 39.81 \\
\hline & $35-44$ & 69 & 31.94 \\
\hline & Over 45 & 23 & 10.65 \\
\hline \multirow{4}{*}{ Education level (EL) } & Primary school & 11 & 5.09 \\
\hline & Junior middle school & 61 & 28.24 \\
\hline & Senior high school (or technical secondary school) & 97 & 44.91 \\
\hline & College degree or above & 47 & 21.76 \\
\hline \multirow{4}{*}{ Personal monthly income (PMI) } & 2000 and below & 14 & 6.48 \\
\hline & 2001-5000 & 102 & 47.22 \\
\hline & 5001-8000 & 70 & 32.40 \\
\hline & 8001 and above & 30 & 13.89 \\
\hline
\end{tabular}

significant, it indicates that the mediating effect of EI is established. Otherwise, the effect is not established, and the test is ended.

When testing the moderating effect of EK and RP, we take ED and EI as dependent variables. In order to test the moderating role of EK and RP in the relationship between $\mathrm{MCE}, \mathrm{EI}$, and ED, the regression model is shown in the following equations:

$$
\begin{aligned}
\mathrm{ED}_{i}= & \theta_{o}+\theta_{1} \mathrm{EL}_{i}+\theta_{2} \mathrm{EK}_{i}+\theta_{3} \mathrm{RP}_{i}+\theta_{4} \mathrm{EK}_{i} \cdot \mathrm{EL}_{i} \\
& +\theta_{5} \mathrm{RP}_{i} \cdot \mathrm{EL}_{i}+\theta_{6} c_{i}+\varepsilon_{i}, \\
\mathrm{EL}_{i}= & \mu_{o}+\mu_{1} \mathrm{MCE}_{i}+\mu_{2} \mathrm{EK}_{i}+\mu_{3} \mathrm{RP}_{i}+\mu_{4} \mathrm{EK}_{i} \cdot \mathrm{MCE}_{i} \\
& +\mu_{5} \mathrm{RP}_{i} \cdot \mathrm{MCE}_{i}+\mu_{6} c_{i}+\varepsilon_{i} .
\end{aligned}
$$

In the above-mentioned formulas, $\mathrm{ED}_{i}$ is the dependent variable; $\mathrm{EL}_{i}$ is the mediator variable; $\mathrm{MCE}_{i}$ is the independent variable; $\mathrm{EK}_{i}$ and $\mathrm{RP}_{i}$ are moderator variables; $c_{i}$ is the control variable; $\varepsilon_{i}$ is the residual; and $\alpha_{i}, \beta_{i}, \gamma_{i}, \theta_{i}$, and $\mu_{i}$ are the effects of each variable, respectively.

3.5. Empirical Results. The study uses the Harman singlefactor test to examine the common method bias. A confirmatory factor analysis of the variables is conducted using AMOS 21.0. The results showed that the single-factor model fits poorly, while the five-factor model fits well (Table 2). A further test is carried out by introducing a common method factor, that is, the five-factor model. In this sense, the sixfactor model is proposed. The results showed that the model cannot fit. Therefore, there is no serious common method bias in the data of this study.

Benchmark model (5 factors): MCE (F1), EI (F2), ED (F3), EK (F4), RP (F5); four-factor model 1: F1, F2, F3 + F4, F5; four-factor model 2: F1, F2 + F4, F3, F5; three-factor model 1: F1, F2, F3 + F4 + F5; three-factor model 2: F1, F2 + F3 + F4, F5; three-factor model 3: F1, F2 + F5, F3 + F4; two-factor model 1: F1, F2 + F3 + F4 + F5; and single-factor model: F1, F2, F3, F4, F5 are combined into one factor; as a latent factor, common method bias was incorporated into the benchmark model.

We apply confirmatory factor analysis to test the reliability and validity of those variables, and the results are presented in Tables 2 and 3. According to Table 2, the model has good fit indicators $\left(\chi^{2}=248.675, \mathrm{df}=142, \chi^{2} / \mathrm{df}=1.751\right.$, $\mathrm{TLI}=0.960, \mathrm{CFI}=0.967, \mathrm{RMSEA}=0.059, \quad \mathrm{SRMR}=0.051$ ), indicating a good fit between the model and the data. The model comparison tool is also used to evaluate the discriminant validity between variables, and the results show that the five-factor model has the best fitting effect on the data compared with the other eight models, which indicates that the scale has good discriminant validity. In Table 3, the composite reliability values of latent variables are greater than 0.7, indicating that the scale has good internal consistency and high reliability and validity. The minimum and maximum factor loads are 0.693 and 0.916 and reach a 
TABLE 2: Discriminant validity and common method bias.

\begin{tabular}{|c|c|c|c|c|c|c|c|c|c|}
\hline \multirow{2}{*}{ Model } & \multirow{2}{*}{$x^{2}$} & \multirow{2}{*}{$\mathrm{df}$} & \multirow{2}{*}{ TLI } & \multirow{2}{*}{ CFI } & \multirow{2}{*}{ RMSEA } & \multirow{2}{*}{ SRMR } & \multicolumn{3}{|c|}{ Model comparison testing } \\
\hline & & & & & & & Model comparison & $\Delta \chi^{2}$ & $\mathrm{df}$ \\
\hline 1. Benchmark model & 248.675 & 142 & 0.960 & 0.967 & 0.059 & 0.051 & & & \\
\hline 2. Four-factor model 1 & 334.513 & 146 & 0.931 & 0.941 & 0.077 & 0.055 & 2 vs 1 & $85.838^{* * *}$ & 4 \\
\hline 3. Four-factor model 2 & 414.243 & 146 & 0.902 & 0.916 & 0.092 & 0.058 & 3 vs 1 & $165.568^{* * *}$ & 4 \\
\hline 4. Three-factor model 1 & 426.174 & 149 & 0.900 & 0.913 & 0.093 & 0.062 & 4 vs 1 & $177.499^{* * *}$ & 7 \\
\hline 5. Three-factor model 2 & 523.346 & 149 & 0.866 & 0.883 & 0.108 & 0.061 & 5 vs 1 & $274.671^{* * *}$ & 7 \\
\hline 6. Three-factor model 3 & 429.486 & 149 & 0.899 & 0.912 & 0.094 & 0.062 & 6 vs 1 & $180.811^{* * *}$ & 7 \\
\hline 7. Two-factor model & 599.307 & 151 & 0.841 & 0.860 & 0.118 & 0.066 & 7 vs 1 & $350.632^{* * *}$ & 9 \\
\hline 8. Single-factor model & 859.112 & 152 & 0.751 & 0.779 & 0.147 & 0.092 & 8 vs 1 & $610.437^{* * *}$ & 10 \\
\hline 9. Six-factor model & & & Mod & cannot $\mathrm{f}$ & & & & & \\
\hline
\end{tabular}

Note: ${ }^{* *} P<0.001$.

TABLE 3: Reliability and validity.

\begin{tabular}{|c|c|c|c|c|c|c|c|c|c|}
\hline Latent variable & Item & Unstd & SE & T-value & $P$ & FL & IIR & $\mathrm{CR}$ & AVE \\
\hline \multirow{4}{*}{ MCE } & $\mathrm{X} 11$ & 1 & & & & 0.693 & 0.480 & \multirow{4}{*}{0.858} & \multirow{4}{*}{0.602} \\
\hline & $\mathrm{X} 12$ & 1.231 & 0.126 & 9.747 & $* * *$ & 0.743 & 0.552 & & \\
\hline & $\mathrm{X} 13$ & 1.369 & 0.129 & 10.644 & $* * *$ & 0.837 & 0.701 & & \\
\hline & $\mathrm{X} 14$ & 1.348 & 0.129 & 10.428 & $* * *$ & 0.822 & 0.676 & & \\
\hline \multirow{4}{*}{ EI } & $\mathrm{X} 21$ & 1 & & & & 0.916 & 0.839 & \multirow{4}{*}{0.927} & \multirow{4}{*}{0.762} \\
\hline & $\mathrm{X} 22$ & 0.949 & 0.049 & 19.181 & $* * *$ & 0.863 & 0.745 & & \\
\hline & $\mathrm{X} 23$ & 0.976 & 0.045 & 21.480 & $* * *$ & 0.907 & 0.823 & & \\
\hline & $\mathrm{X} 24$ & 0.924 & 0.058 & 16.038 & $* * *$ & 0.800 & 0.640 & & \\
\hline \multirow{4}{*}{$\mathrm{ED}$} & $\mathrm{X} 31$ & 1 & & & & 0.884 & 0.781 & \multirow{4}{*}{0.925} & \multirow{4}{*}{0.755} \\
\hline & X32 & 0.947 & 0.049 & 19.237 & $* * *$ & 0.899 & 0.808 & & \\
\hline & X33 & 0.914 & 0.057 & 15.936 & $* * *$ & 0.818 & 0.669 & & \\
\hline & $\mathrm{X} 34$ & 0.932 & 0.052 & 17.907 & $* * *$ & 0.873 & 0.762 & & \\
\hline \multirow{4}{*}{ EK } & $\mathrm{X} 41$ & 1 & & & & 0.855 & 0.731 & \multirow{4}{*}{0.900} & \multirow{4}{*}{0.693} \\
\hline & $\mathrm{X} 42$ & 1.006 & 0.060 & 16.848 & $* * *$ & 0.872 & 0.760 & & \\
\hline & $\mathrm{X} 43$ & 0.948 & 0.069 & 13.824 & $* * *$ & 0.783 & 0.613 & & \\
\hline & $\mathrm{X} 44$ & 0.960 & 0.066 & 14.626 & $* * *$ & 0.818 & 0.669 & & \\
\hline \multirow{3}{*}{$\mathrm{RP}$} & $\mathrm{X} 51$ & 1 & & & & 0.787 & 0.619 & \multirow{3}{*}{0.819} & \multirow{3}{*}{0.603} \\
\hline & X52 & 1.066 & 0.092 & 11.565 & $* * *$ & 0.841 & 0.707 & & \\
\hline & $\mathrm{X} 53$ & 0.813 & 0.083 & 9.847 & $* * *$ & 0.696 & 0.484 & & \\
\hline
\end{tabular}

Note: ${ }^{* * *} P<0.001$.

significant level of $1 \%$, which meets the interval requirements of factor load in the range of 0.5 to 0.95 . The average variance extraction value is greater than 0.5 , which proves the scale has good convergence validity.

Table 4 presents the means, standard deviations, and Pearson correlations of all variables. These results provide initial support for us to verify our hypotheses.

The result in model 6 in Table 5 shows that MCE has a positive and significant influence on the EI of RMWs $(\beta=0.689, P<0.001)$. Thus, hypothesis 1 is supported. This indicates that the media can influence the EI of RMWs through positive coverage. The result in model 3 in Table 5 shows that the EI of RMWs has a positive and significant impact on ED $(\beta=0.692, P<0.001)$. Thus, hypothesis 2 is supported.

We test the mediating effect of EI according to the method proposed by Kenny [51]. As shown in model 2 in Table 5, the MCE has a significant positive impact on the ED of RMWs $(\beta=0.562, P<0.001$, model 2$)$. Thus, hypothesis 3 is supported. The results in model 4 in Table 5 show that the EI has a significant positive impact on ED of RMWs $(\beta=0.652, \quad P<0.001)$. Meanwhile, the MCE has no
TABle 4: Descriptive statistics and correlation analysis of key variables.

\begin{tabular}{lccccccr}
\hline & $\mathrm{M}$ & $\mathrm{SD}$ & 1 & 2 & 3 & 4 & 5 \\
\hline 1. MCE & 3.262 & 0.854 & 1 & & & & \\
2. EI & 2.894 & 1.235 & $0.498^{* * *}$ & 1 & & & \\
3. ED & 2.105 & 1.142 & $0.451^{* * *}$ & $0.753^{* * *}$ & 1 & & \\
4. EK & 2.567 & 1.121 & $0.392^{* * *}$ & $0.752^{* * *}$ & $0.794^{* * *}$ & 1 & \\
5. RP & 3.015 & 1.018 & $0.365^{* * *}$ & $0.653^{* * *}$ & $0.619^{* * *}$ & $0.632^{* * *}$ & 1 \\
\hline
\end{tabular}

Note: ${ }^{* * *} P<0.001$.

significant impact on $\operatorname{ED}(\beta=0.112, P>0.05$, model 4$)$. In the case where hypothesis 1 has been confirmed, the abovementioned analysis shows that the EI plays a completely mediating role between MCE and ED of RMWs. Thus, hypothesis 4 is supported. It shows that MCE can indirectly affect the ED of RMWs through their EIs.

The result in model 6 in Table 6 shows that EK negatively moderates the relationship between MCE and EI of RMWs $(\beta=-0.169, P<0.01)$. Thus, hypothesis $5 \mathrm{a}$ is supported. RP positively moderates the relationship between MCE and EI 
TABle 5: Mediating effect of EI.

\begin{tabular}{|c|c|c|c|c|c|c|}
\hline \multirow{2}{*}{ Variables } & \multicolumn{4}{|c|}{ ED } & \multicolumn{2}{|c|}{ EI } \\
\hline & Model 1 & Model 2 & Model 3 & Model 4 & Model 5 & Model 6 \\
\hline Gender & $-0.439^{* *}$ & $-0.326^{*}$ & -0.008 & -0.010 & $-0.622^{* * *}$ & $-0.484^{* * *}$ \\
\hline Age & -0.153 & -0.079 & $-0.172^{* *}$ & $-0.102^{*}$ & 0.027 & 0.118 \\
\hline EL & -0.192 & -0.146 & -0.121 & -0.116 & -0.103 & -0.046 \\
\hline PMI & 0.169 & 0.143 & 0.057 & 0.058 & 0.162 & 0.130 \\
\hline MCE & & $0.562^{* * *}$ & & 0.112 & & $0.689^{* * *}$ \\
\hline EI & & & $0.692^{* * *}$ & $0.652^{* * *}$ & & \\
\hline $\mathrm{F}$ & $4.371^{* *}$ & $13.815^{* * *}$ & $58.613^{* * *}$ & $49.660^{* * *}$ & $4.371^{* * *}$ & $13.815^{* * *}$ \\
\hline$R^{2}$ & 0.077 & 0.248 & 0.583 & 0.588 & 0.077 & 0.248 \\
\hline Adjustment $R^{2}$ & 0.059 & 0.230 & 0.573 & 0.576 & 0.059 & 0.230 \\
\hline
\end{tabular}

Notes: ${ }^{*} P<0.05:{ }^{* *} P<0.01 ;{ }^{* * *} P<0.001$.

TABLE 6: Moderating effect of EK and RP.

\begin{tabular}{|c|c|c|c|c|c|c|}
\hline \multirow{2}{*}{ Variables } & \multicolumn{3}{|c|}{ ED } & \multicolumn{3}{|c|}{ EI } \\
\hline & Model 1 & Model 2 & Model 3 & Model 4 & Model 5 & Model 6 \\
\hline Gender & $-0.439^{* *}$ & -0.007 & -0.004 & -0.622 & $-0.246^{*}$ & $-0.232^{*}$ \\
\hline Age & -0.153 & -0.043 & -0.052 & 0.027 & $0.230^{* * *}$ & $0.256^{* * *}$ \\
\hline EL & -0.192 & -0.011 & -0.039 & -0.103 & 0.103 & 0.109 \\
\hline PMI & 0.169 & 0.027 & 0.013 & 0.162 & 0.006 & 0.017 \\
\hline MCE & & & & & $0.306^{* * *}$ & $0.314^{* * *}$ \\
\hline EI & & $0.303^{* * *}$ & $0.332^{* * *}$ & & & \\
\hline EK & & $0.494^{* * *}$ & $0.416^{* * *}$ & & $0.544^{* * *}$ & $0.553^{* * *}$ \\
\hline $\mathrm{RP}$ & & 0.103 & 0.101 & & $0.322^{* * *}$ & $0.330^{* * *}$ \\
\hline $\mathrm{EK} * \mathrm{MCE}$ & & & & & & $-0.169^{* *}$ \\
\hline $\mathrm{RP}^{*} \mathrm{MCE}$ & & & & & & $0.127^{*}$ \\
\hline $\mathrm{EK} * \mathrm{EI}$ & & & $0.109^{* *}$ & & & \\
\hline $\mathrm{RP}^{*} \mathrm{EI}$ & & & $0.092^{*}$ & & & \\
\hline $\mathrm{F}$ & $4.371^{* *}$ & $67.266^{* * *}$ & $64.608^{* * *}$ & $5.639^{* * *}$ & $64.846^{* * *}$ & $52.654^{* * *}$ \\
\hline$R^{2}$ & 0.077 & 0.694 & 0.738 & 0.097 & 0.686 & 0.697 \\
\hline Adjustment $R^{2}$ & 0.059 & 0.683 & 0.727 & 0.079 & 0.675 & 0.684 \\
\hline
\end{tabular}

Notes: ${ }^{*} P<0.05,{ }^{* *} P<0.01,{ }^{* * *} P<0.001$.

of RMWs $(\beta=0.127, P<0.05)$, and thus hypothesis $6 \mathrm{a}$ is supported.

Then, we test the moderating effect of EK and RP on the relationship between EI and ED of RMWs. The result in model 3 in Table 6 shows that EK positively moderates the relationship between EI and ED of RMWs $(\beta=0.109$, $P<0.01)$. Thus, hypothesis $5 \mathrm{~b}$ is supported. RP positively moderates the relationship between EI and ED of RMWs $(\beta=0.092, P<0.05)$. Thus, hypothesis $6 \mathrm{~b}$ is supported.

We draw the moderating effect diagram by adding or subtracting a standard deviation from the mean value of the moderator variables. Figures 2 and 3 show that EK negatively moderates the relationship between MCE and EI, while RP positively moderates the relationship between EI and ED. The results in Figures 4 and 5 show that both EK and RP positively moderate the relationship between EI and ED.

The PROCESS program developed by Hayes is used to test the moderated mediating effect. We apply the bootstrap method, bootstrapping 5000 samples to compute 95\% biascorrected confidence intervals. If the confidence interval excludes 0 , the indirect effect is significant. The results are shown in Table 7 . When the RMWs lack EK, the indirect effect of MCE on ED through EI is not significant, $\beta=0.032$, and the $95 \%$ bias-corrected confidence intervals are $(-0.009$,

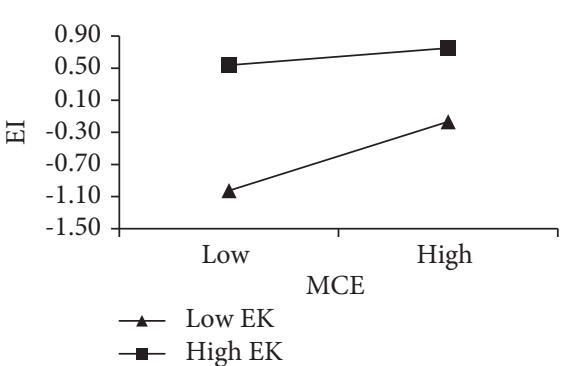

FIGURE 2: Moderating effect of EK on the relationship between MCE and EI of RMWs.

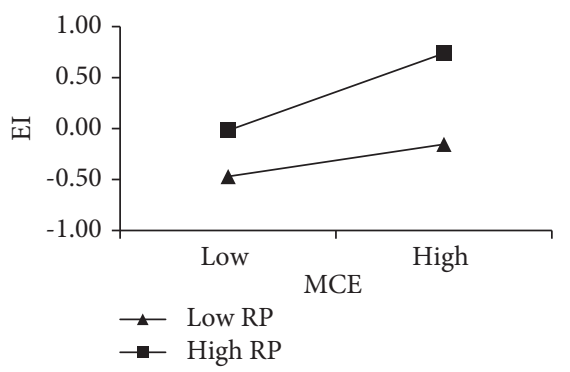

FIgURE 3: Moderating effect of RP on the relationship between MCE and EI of RMWs. 


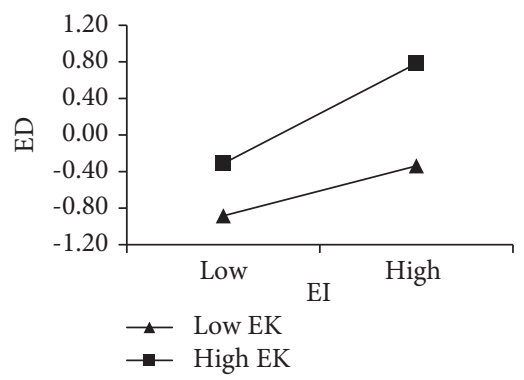

FIGURE 4: Moderating effect of EK on the relationship between EI and ED of RMWs.

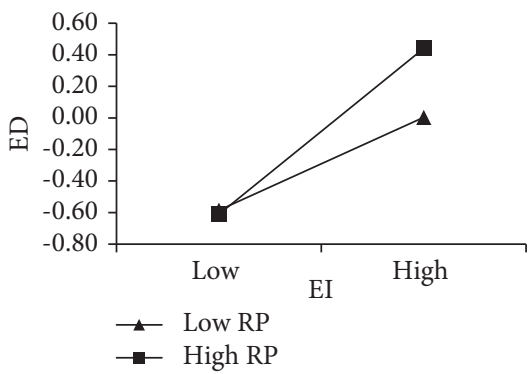

FIGURE 5: Moderating effect of RP on the relationship between EI and ED of RMWs.

TABLE 7: Bootstrap method for testing moderated mediating effect.

\begin{tabular}{lcccc}
\hline Moderator variables & Indirect effect & Standard error & Lower bound & Upper bound \\
\hline Lack of EK (mean - 1 SD) & 0.032 & 0.021 & -0.009 & 0.076 \\
Richness in EK (mean + 1 SD) & 0.141 & 0.067 & 0.029 & 0.290 \\
Low RP (mean-1 SD) & 0.045 & 0.029 & -0.007 & 0.106 \\
High RP (mean + 1 SD) & 0.146 & 0.049 & 0.058 & 0.250 \\
\hline
\end{tabular}

0.076), including 0 . When the RMWs are rich in $\mathrm{EK}$, the indirect effect of MCE on ED through EI is significant, $\beta=0.141$, and the $95 \%$ bias-corrected confidence intervals are $(0.029,0.290)$, excluding 0 . Therefore, hypothesis 7 is confirmed. When the RMWs have low RP, the indirect effect of MCE on ED through EI is not significant, $\beta=0.045$, and the $95 \%$ bias-corrected confidence intervals are $(-0.007$, $0.106)$, including 0 . When the RMWs have high RP, the indirect effect of MCE on ED through EI is significant, $\beta=0.146$, and the $95 \%$ bias-corrected confidence intervals are $(0.058,0.250)$, excluding 0 . Therefore, hypothesis $7 \mathrm{~b}$ is confirmed.

\section{Conclusion and Discussion}

In this paper, MCE has a positive and significant impact on the EI and ED of RMWs. EI plays a complete mediating role in the relationship between MCE and ED. When RMWs have a certain EK, the EI will be less affected by MCE. When RMWs have a certain EI, the richer their EK is, the easier they can make entrepreneurial decisions. EK positively moderates the mediating effect of EI. RP strengthens the positive impact of MCE on the EI, enhances the positive impact of the EI on ED, and has a positive moderating effect on the mediating process of the EI.

This study made three main theoretical contributions. Firstly, we investigated the agenda-setting effect of MCE on helping RMWs to start a business. However, early studies focused more on the impact of business reports on business operations [52]. Secondly, this study used EI as a mediator variable to examine the causal relationship between MCE and EI and ED of RMWs, but previous studies mainly took it as a dependent variable [53]. Thirdly, although some studies had pointed out that there was agenda-setting effect in the field of business communication [54], they have not revealed the contingency factors affecting this effect. This study examined the moderating effect of EK and RP, which enriched the existing studies.

The conclusions of this study have some policy implications. The media should accurately build the coverage content, tell the touching story of entrepreneurship and effective entrepreneurial models, and constantly improve the effect of agenda setting. More importantly, the media should differentiate MCE for RMWs with different EKs and RP, so as to help RMWs establish entrepreneurial knowledge system and entrepreneurial risk prevention system.

This study has some limitations. There is no maturity scale in the measurement of MCE. This study mainly approached ED from discovering and making use of opportunities and thus lacked dynamic investigation into this social issue. In addition, MCE in this study refers mainly to the positive reports. Therefore, future research is needed to examine different media, different coverage topics, and different coverage tendencies. More work is also needed to 
explore the differences in the effect of agenda setting, which could deepen the current research.

\section{Data Availability}

The data used to support the findings of this study have been deposited in FAIRsharing.org. Please visit https://beta. fairsharing.org/3627. The data can be also downloaded directly from the permanent link https://gl.qfnu.edu.cn/info/ $1014 / 2017 . h t m$ and are available from the corresponding author upon request.

\section{Conflicts of Interest}

The authors declare that they have no conflicts of interest.

\section{Acknowledgments}

This research was supported by the Education Youth Project of the National Social Science Foundation of China (Grant no. CKA150136) and a Project of Shandong Province Higher Educational Science and Technology Program (Grant no. J15WB03).

\section{References}

[1] Q. Lin and Q. Mai, "How to improve new generation migrant workers' entrepreneurial willingness-A moderated mediation examination from the sustainable perspective," Sustainability, vol. 10, no. 5, pp. 1578-1590, 2018.

[2] S. Iyengar, "Television news and issue salience," American Politics Quarterly, vol. 7, no. 4, pp. 395-416, 1979.

[3] V. P. Rindova, T. G. Pollock, and M. L. A. Hayward, "Celebrity firms: the social construction of market popularity," Academy of Management Review, vol. 31, no. 1, pp. 50-71, 2006.

[4] L. Nicholson and A. R. Anderson, "News and nuances of the entrepreneurial myth and metaphor: linguistic games in entrepreneurial sense-making and sense-giving," Entrepreneurship: Theory and Practice, vol. 29, no. 2, pp. 153-172, 2010.

[5] T. G. Pollock and V. P. Rindova, "Media legitimation effects in the market for initial public offerings," Academy of Management Journal, vol. 46, no. 5, pp. 631-642, 2003.

[6] P. C. Tetlock, "Giving content to investor sentiment: the role of media in the stock market," The Journal of Finance, vol. 62, no. 3, pp. 1139-1168, 2007.

[7] A. Tezel, E. Papadonikolaki, I. Yitmen, and P. Hilletofth, "Preparing construction supply chains for blockchain technology: an investigation of its potential and future directions," Frontiers of Engineering Management, vol. 7, no. 4, pp. 547-563, 2020.

[8] S. Mullainathan and A. Shleifer, "The market for news," The American Economic Review, vol. 95, no. 4, pp. 1031-1053, 2005.

[9] M. L. A. Hayward, V. P. Rindova, and T. G. Pollock, "Believing one's own press: the causes and consequences of CEO celebrity," Strategic Management Journal, vol. 25, no. 7, pp. 637-653, 2004.

[10] B. Nguyen, X. Yu, T. C. Melewar, and J. Chen, "Brand innovation and social media: knowledge acquisition from social media, market orientation, and the moderating role of social media strategic capability," Industrial Marketing Management, vol. 51, no. 11, pp. 11-25, 2015.
[11] P. Kjær and R. Langer, "Infused with news value: management, managerial knowledge and the institutionalization of business news," Scandinavian Journal of Management, vol. 21, no. 2, pp. 209-233, 2005.

[12] M. E. McCombs and D. Shaw, "The agenda-setting function of the mass media," Public Opinion Quarterly, vol. 36, no. 2, pp. 813-824, 1972.

[13] M. Radu and R. Redien-Collot, "The social representation of entrepreneurs in the French press," International Small Business Journal: Researching Entrepreneurship, vol. 26, no. 3, pp. 259-298, 2008.

[14] C. E. Carroll and M. McCombs, "Agenda-setting effects of business news on the public's images and opinions about major corporations," Corporate Reputation Review, vol. 6, no. 1, pp. 36-46, 2003.

[15] V. P. Rindova, I. O. Williamson, A. P. Petkova, and J. M. Sever, "Being good or being known: an empirical examination of the dimensions, antecedents, and consequences of organizational reputation," Academy of Management Journal, vol. 48, no. 6, pp. 1033-1049, 2005.

[16] Y. Gao, Z. Feng, and S. Zhang, "Managing supply chain resilience in the era of VUCA," Frontiers of Engineering Management, vol. 8, no. 3, pp. 465-470, 2021.

[17] N. Bosma, J. Hessels, V. Schutjens, M. V. Praag, and I. Verheul, "Entrepreneurship and role models," Journal of Economic Psychology, vol. 33, no. 2, pp. 410-424, 2012.

[18] I. Ajzen, "The theory of planned behaviour: reactions and reflections," Psychology and Health, vol. 26, no. 9, pp. 1113-1127, 2011.

[19] J. E. McGee, M. Peterson, S. L. Mueller, and J. M. Sequeira, "Entrepreneurial self-efficacy: refining the measure," Entrepreneurship: Theory and Practice, vol. 33, no. 4, pp. 965-988, 2009.

[20] B. Feng and Q. Ye, "Operations management of smart logistics: a literature review and future research," Frontiers of Engineering Management, vol. 8, no. 3, pp. 344-355, 2021.

[21] L. Kolvereid, "Preference for self-employment," The International Journal of Entrepreneurship and Innovation, vol. 17, no. 2, pp. 100-109, 2016.

[22] D. McQuail, Mass Communication Theory: An Introduction, Sage, Thousand Oaks, CA, USA, 1994.

[23] B. J. Brian, J. E. Core, W. R. Guay, and S. Hamm, "The role of the business press as an information intermediary," Journal of Accounting Research, vol. 48, no. 1, pp. 1-19, 2010.

[24] O. E. Williamson, "The new institutional economics: taking stock, looking ahead," Journal of Economic Literature, vol. 38, no. 3, pp. 595-613, 2000.

[25] B. M. K. Mwiya, Y. Wang, B. Kaulungombe, and M. Kayekesi, "Exploring entrepreneurial intention's mediating role in the relationship between self-efficacy and nascent behaviour," Journal of Small Business and Enterprise Development, vol. 26, no. 4, pp. 466-485, 2019.

[26] H. Bergmann and R. Sternberg, "The changing face of entrepreneurship in Germany," Small Business Economics, vol. 28, no. 2, pp. 205-221, 2007.

[27] D. Politis, "The process of entrepreneurial learning: a conceptual framework," Entrepreneurship: Theory and Practice, vol. 29, no. 4, pp. 399-424, 2005.

[28] B. Roxas, "Effects of entrepreneurial knowledge on entrepreneurial intentions: a longitudinal study of selected Southeast Asian business students," Journal of Education and Work, vol. 27, no. 4, pp. 432-453, 2014.

[29] J. Wu, J. Sun, and L. Liang, "Methods and applications of DEA cross-efficiency: review and future perspectives," 
Frontiers of Engineering Management, vol. 8, no. 2, pp. 199-211, 2021.

[30] Y. Tsfati, "Does audience skepticism of the media matter in agenda setting?" Journal of Broadcasting \& Electronic Media, vol. 47, no. 2, pp. 157-176, 2003.

[31] E. K. Roger, R. Ortwin, S. Paul et al., "The social amplification of risk: a conceptual framework," Risk Analysis, vol. 8, no. 2, pp. 177-187, 1988.

[32] S. A. Alvarez and L. W. Busenitz, "The entrepreneurship of resource-based theory," Journal of Management, vol. 27, no. 6, pp. 755-775, 2001.

[33] T. Wing Yan Man, "Developing a behaviour-centred model of entrepreneurial learning," Journal of Small Business and Enterprise Development, vol. 19, no. 3, pp. 549-566, 2012.

[34] Y. Bian, D. Lemoine, T. G. Yeung, and N. Bostel, "Two-level uncapacitated lot-sizing problem considering the financing cost of working capital requirement," Frontiers of Engineering Management, vol. 7, no. 2, pp. 248-258, 2020.

[35] S. B. Sitkin and L. R. Weingart, "Determinants of risky decision-making behavior: a test of the mediating role of risk perceptions and propensity," Academy of Management Journal, vol. 38, no. 6, pp. 1573-1592, 1995.

[36] S. B. Sitkin and A. L. Pablo, "Reconceptualizing the determinants of risk behavior," Academy of Management Review, vol. 17, no. 1, pp. 9-39, 1992.

[37] A. Mazur, "Risk perception and news coverage across nations," Risk Management, vol. 8, no. 3, pp. 149-174, 2006.

[38] J. G. March and Z. Shapira, "Managerial perspectives on risk and risk taking," Management Science, vol. 33, no. 11, pp. 1404-1418, 1987.

[39] X. S. Xu, F. T. S. Chan, and C. K. Chan, "Optimal option purchase decision of a loss-averse retailer under emergent replenishment," International Journal of Production Research, vol. 57, no. 4, pp. 4594-4620, 2019.

[40] E. U. Weber, C. J. Anderson, and M. H. Birnbaum, "A theory of perceived risk and attractiveness," Organizational Behavior and Human Decision Processes, vol. 52, no. 3, pp. 492-523, 1992.

[41] R. K. Mitchell, L. Busenitz, T. Lant, P. P. McDougall, E. A. Morse, and J. B. Smith, "Toward a theory of entrepreneurial cognition: rethinking the people side of entrepreneurship research," Entrepreneurship: Theory and Practice, vol. 27, no. 2, pp. 93-104, 2002.

[42] X. Xu, H. Wang, C. Dang, and P. Ji, “The loss-averse newsvendor model with backordering," International Journal of Production Economics, vol. 188, no. 6, pp. 1-10, 2017.

[43] L. W. Busenitz and J. B. Barney, "Differences between entrepreneurs and managers in large organizations: biases and heuristics in strategic decision-making," Journal of Business Venturing, vol. 12, no. 1, pp. 9-30, 1997.

[44] X. Xu, C. K. Chan, and A. Langevin, "Coping with risk management and fill rate in the loss-averse newsvendor model," International Journal of Production Economics, vol. 195, no. 10, pp. 296-310, 2018.

[45] S. M. Farmer, X. Yao, and K. Kung-Mcintyre, "The behavioral impact of entrepreneur identity aspiration and prior entrepreneurial experience," Entrepreneurship: Theory and Practice, vol. 35, no. 2, pp. 245-273, 2011.

[46] R. J. Baldegger, S. Alberton, and F. Hacklin, "Global entrepreneurship monitor 2011-report on Switzerland," Executive Report, Babson College-London Business School, Babson Park, MA, USA, 2012.

[47] F. Liñán and Y. W. Chen, "Development and cross-cultural application of a specific instrument to measure entrepreneurial intentions," Entrepreneurship: Theory and Practice, vol. 33, no. 3, pp. 593-617, 2009.

[48] C. R. D. Rosário, L. M. Kipper, R. Frozza, and B. B. Mariani, "Modeling of tacit knowledge in industry: simulations on the variables of industrial processes," Expert Systems with Applications, vol. 42, no. 3, pp. 1613-1625, 2015.

[49] H. Zhao, S. E. Seibert, and G. E. Hills, "The mediating role of self-efficacy in the development of entrepreneurial intentions," Journal of Applied Psychology, vol. 90, no. 6, pp. 1265-1272, 2005.

[50] A. Paço, J. M. Ferreira, M. Raposo, R. G. Rodrigues, and A. Dinis, "Entrepreneurial intentions: is education enough?" The International Entrepreneurship and Management Journal, vol. 11, no. 1, pp. 57-75, 2013.

[51] R. M. Baron and D. A. Kenny, "The moderator-mediator variable distinction in social psychological research: conceptual, strategic, and statistical considerations," Journal of Personality and Social Psychology, vol. 51, no. 6, pp. 1173-1182, 1986.

[52] J. R. Joe, H. Louis, and D. Robinson, "Managers' and investors' responses to media exposure of board ineffectiveness," Journal of Financial and Quantitative Analysis, vol. 44, no. 3, pp. 579-605, 2009.

[53] N. F. Kruegerjr, M. D. Reilly, and A. L. Carsrud, "Competing models of entrepreneurial intentions," Journal of Business Venturing, vol. 15, no. 5, pp. 411-432, 2000.

[54] R. M. Entman, "Framing: toward clarification of a fractured paradigm," Journal of Communication, vol. 43, no. 4, pp. 51-58, 1993. 